Review

\title{
Current Understanding of Dolichoarteriopathies of the Internal Carotid Artery: A Review
}

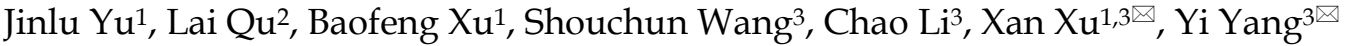 \\ 1. Department of Neurosurgery, The First Hospital of Jilin University, Changchun, 130021, P.R. China \\ 2. Department of Intensive Care Unit, The First Hospital of Jilin University, Changchun, 130021, P.R. China \\ 3. Neuroscience Center, Stroke Center, Department of Neurology, The First Hospital of Jilin University, Changchun, 130021, P.R. China
}

$\square$ Corresponding author: Yi Yang and Xan Xu, Neuroscience Center, Stroke Center, The First Hospital of Jilin University, Xinmin Street \#71, Changchun 130021, China. Email: jlyu@jlu.edu.cn

(c) Ivyspring International Publisher. This is an open access article distributed under the terms of the Creative Commons Attribution (CC BY-NC) license (https://creativecommons.org/licenses/by-nc/4.0/). See http://ivyspring.com/terms for full terms and conditions.

Received: 2017.01.17; Accepted: 2017.04.23; Published: 2017.07.18

\begin{abstract}
Dolichoarteriopathies of the internal carotid artery (DICAs) are not uncommon, and although several studies have investigated DICAs, several questions regarding the etiology and best management course for DICAs remain unanswered. It is also difficult to correlate the occurrence of DICAs with the onset of clinical symptoms. Therefore, we surveyed the literature in PubMed and performed a review of DICAs to offer a comprehensive picture of our understanding of DICAs. We found that DICAs can be classified into three types, specifically tortuous, coiling and kinking, and are not associated with atherosclerotic risk factors. Cerebral hemodynamic changes are mainly associated with the degree of bending of DICAs. DICAs can result in symptoms of the brain and eyes due to insufficient blood supply and can co-occur with a pulsatile cervical mass, a pharyngeal bulge and pulsation. The diagnostic tools for the assessment of DICAs include Doppler ultrasonography, computed tomography angiography (CTA), magnetic resonance angiography (MRA) and digital subtraction angiography (DSA), and although DSA remains the gold standard, Doppler ultrasonography is a convenient method that provides useful data for the morphological evaluation of DICAs. CTA and MRA are efficient methods for detecting the morphology of the cervical segment of DICAs. Some DICAs should be treated surgically based on certain indications, and several methods, including correcting the bending or shortening of DICAs, have been developed for the treatment of DICAs. The appropriate treatment of DICAs results in good outcomes and is associated with low morbidity and mortality rates. However, despite the success of surgical reconstruction, an appropriate therapeutic treatment remains a subject of numerous debates due to the lack of multicentric, randomized, prospective studies.
\end{abstract}

Key words: Dolichoarteriopathy, Internal Carotid Artery, Treatment, Review

\section{Introduction}

Dolichoarteriopathies of the internal carotid artery (DICAs), which seldom involve the external carotid artery, can be divided into three types: tortuous, coiling and kinking [1]. DICAs are not uncommon because they occur in $10-25 \%$ of the population [1, 2]. In a large study of 1220 Italian subjects examined by Pellegrino et al. in 1998, 316 presented with DICA, corresponding to an incidence rate of $25.9 \%$, indicating that the reported DICA incidence rates are consistent [3]. Little is known regarding the natural history and clinical course of
DICAs because some DICAs are not associated with any symptoms and present with a benign natural history. In this case, operative intervention is rarely required, and conservative treatment can be administered. However, other DICAs can be disabling or even fatal and thus require surgical treatment to prevent occlusion of the ICA [4-6]. Many doubts remain regarding the etiology and best course of management for DICAs because it is difficult to correlate DICAs with the onset of clinical symptoms $[7,8]$. Therefore, we surveyed the studies on PubMed 
and performed a review of DICAs to offer a comprehensive picture of our understanding of DICAs.

\section{Definition}

The cervical portion of the ICA has two points of fixation, specifically at the bifurcation and at the entry into the pyramid bone, and DICAs can occur if the vessel is longer than the distance between these two points $[9,10]$. DICAs are characterized by anomalous elongation. Metz et al. (1961) and Weibel et al. (1965) classified DICAs into three types, namely tortuous, coiling and kinking [11-13]. (i) The tortuosity was subclassified into elongation, redundancy and undulation depending on whether the ICA develops one or more loops and assumes an "S" or "C" shape. In some cases, the tortuous type includes the coiling or kinking types. (ii) Coiling is characterized by elongation of the ICA in a restricted space, which causes tortuosity and results in a " $\mathrm{C}$ ", "S", or "U" shape or a circular (or double circular) configuration. (iii) Kinking is the most frequent morphological anomaly and presents as a variant of coiling. In addition, kinking presents as a sharp angulation of the first portion of the ICA. The different types of DICAs are shown in Figure 1.

Furthermore, according to Metz et al., kinking can be divided into three grades. Grade I abnormality indicates an acute angle of $90^{\circ}-60^{\circ}$ between the two segments forming the kink, grade II indicates an angle of $60^{\circ}-30^{\circ}$, and grade III indicates an angle less than $30^{\circ}$ [13-16]. The grades of kinking are shown in Figure 2. Kinking and coiling can transition into other DICA types depending on the imaging projection, and mixed forms of DICAs can occur. In addition, the amount of kinking or coiling can be decreased or increased by the position of the head [17].

\section{Hemodynamics}

DICAs can reduce the blood supply to the brain through decreases in blood pressure, which often do not lead to cerebral ischemia due to compensation of the self-regulatory mechanism in the cerebral blood supply. However, when the self-regulatory mechanism is weakened or decompensation occurs due to factors such as atherosclerosis, hypertension, diabetes or old age, cerebral ischemia can occur [18, 19]. In fact, cerebral ischemia from DICAs occurs through two mechanisms: a thromboembolic mechanism from endothelial lesions due to changes in the local flow at the site of arterial bending, and a hemodynamic mechanism that plays an important role under both neutral and dynamic conditions [20].

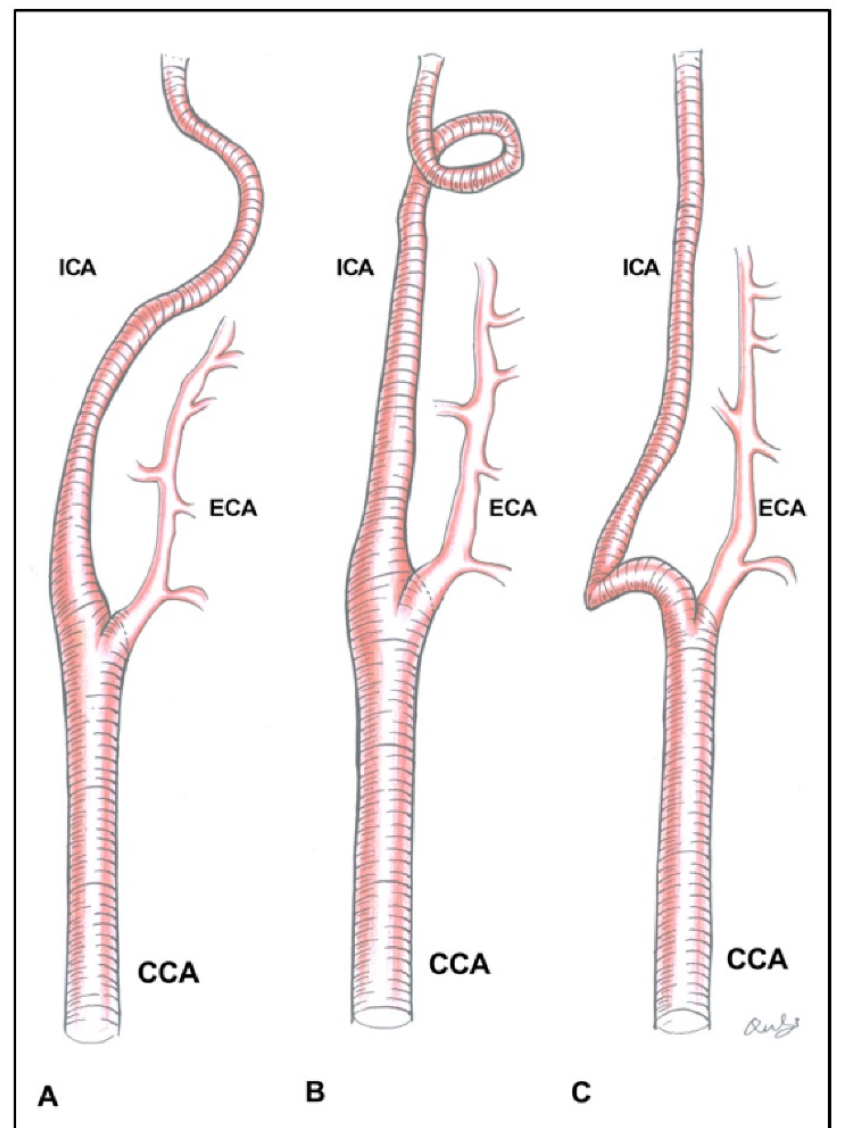

Figure 1. Types of DICAs. A: Tortuous, B: Coiling, C: Kinking. CCA: common carotid artery, ECA: external carotid artery, ICA: internal carotid artery

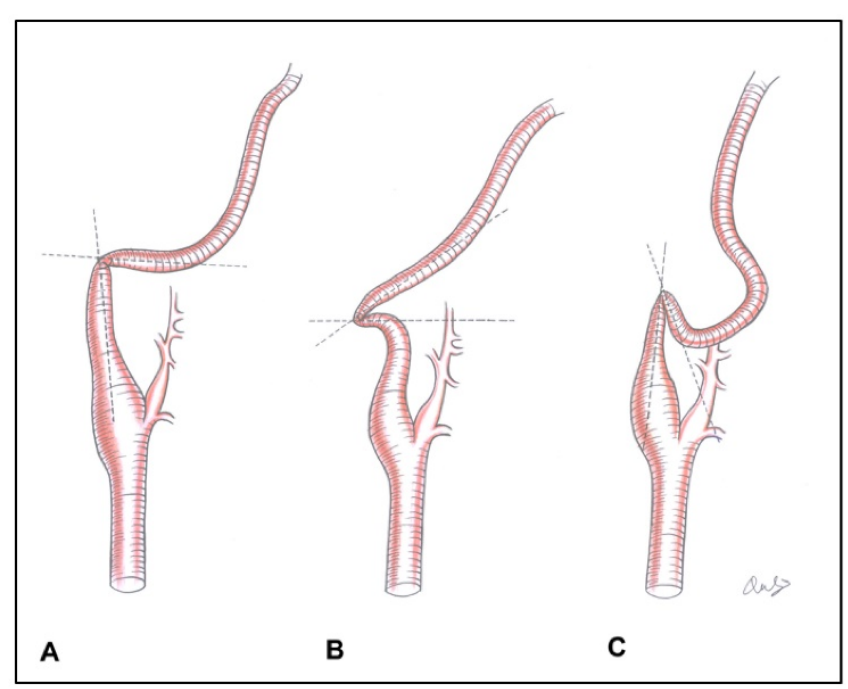

Figure 2. Grades of kinking. A: Grade I, B: Grade II, C: Grade III.

The cerebral hemodynamic changes are mainly associated with the degree of bending of DICAs. The blood flow can be reduced by more than $40 \%$ with an ICA angle of $60^{\circ}$ and by more than $60 \%$ with an ICA angle of $30^{\circ}$ [21]. In addition, Kaplan et al. (2013) found that hemodynamic alterations depend more on the internal surface of the vascular wall in vessels 
with a smooth turn angle of $90^{\circ}$, and that the blood flow might decrease significantly when the DICA is associated with intimal proliferation, atherosclerotic plaque and stenosis. In vessels with an angle of less than $90^{\circ}$, the cerebral hemodynamic reduction mainly depends on the value of the angle of a smooth turn [22].

In addition, in DICAs, transient hypotension, such as that occurring during sleep, upon neck extension or bending or a during turning the head from side to side, can make the ICA collapse at the point of maximal angulation and reduce the blood flow to cause cerebral ischemia [20, 23]. If the DICAs are associated with aneurysms, the cerebral hemodynamics can become more complex [24-26].

\section{Pathogenesis}

Extracranial ICA is a segment of transition between the elastic vessel of the common carotid artery and the muscular vessel of the intracranial ICA, and DICAs might occur when the extracranial ICA displays metaplastic transformation [27]. However, the etiology of metaplastic transformation remains controversial. Many factors, including embryological maldevelopment and age-related loss of elasticity in the vessel wall, are involved in DICAs [28, 29]. However, the loss of elasticity is not synchronous. Greater elongation of the muscular layer of the ICA compared with the adventitia results in bending of the artery, including tortuosity and stenosis [30].

\subsection{Risk factors}

DICAs are theoretically associated with atherosclerotic risk factors, including hypertension, hypercholesterolemia, diabetes mellitus and cigarette smoking. [31-35]. However, some studies have found that these cardiovascular atherosclerotic risk factors do not occur more frequently in patients with DICAs than in patients without DICAs; therefore, the role of hypertension or other cardiovascular risk factors in the genesis of DICAs remains unknown [36-38]. In addition, myointimal thickness and carotid plaques do not show any significant bilateral differences compared with monolateral DICAs [39].

\subsection{Acquired factors}

ICAs become elongated and tortuous with advancing age, and age is thus considered an acquired risk factor for DICA. One of the reasons for this finding is that the heart and major vessels can be dislocated and lifted slightly with increasing age, and the ICAs thus elongate and kink to adapt to the anatomical changes [40]. In addition, with increasing age, the bulb diameter, tortuosity and bifurcation angle increase in non-diseased carotid arteries due to the degradation and fragmentation of intramural elastin [41]. Moreover, another risk factor is the decreased height of the vertebral body and discs with advancing age, which results in shortening of the neck [42]. In addition, obesity can result in remodeling of the carotid arteries [43].

In addition to age, many other acquired risk factors can cause ICA tortuosity, including cervical radiation and carotid artery dissection. Cervical radiation can induce changes in ICA tissue and can result in anatomical distortion [44]. In addition, DICAs might be associated with carotid artery dissection [45, 46], which might occur due to impaired endothelial-dependent vasodilation [47]. For instance, Saba et al. (2015) studied the association between ICA dissection and arterial tortuosity and found that the presence of kinking and coiling are morphological manifestations associated with ICA dissection [48]. In addition, increased blood flow is associated with the degree of tortuosity of the cervical segment of ICAs. Hamada et al. (1997) found that the tortuosity of the ICA is severe in large AVMs [49].

\subsection{Congenital factors}

Congenital factors can contribute to the development of DICAs. A study examining their prevalence among newborn infants, children, adolescents and adults showed that DICAs might have an embryological origin, and this observation is supported by a lack of correlation with cardiovascular risk factors [50]. The co-occurrence of DICAs and other anatomical variations also suggests that DICAs might have a congenital cause [51].

\section{(1) Genetic disease}

Embryological maldevelopment could be involved in the development of DICAs. For instance, Voevoda et al. (2012) reported an association between the A80807T polymorphism of the transcription factor Sp4 and pathological tortuosity of ICAs [52]. In addition, in some familial diseases, the ICA can demonstrate signs of DICAs. For instance, Zaidi et al. (2005) described a family that exhibited arterial tortuosity syndrome. The ICA showed tortuosity, and the affected family members included in the study displayed homozygosity for markers located at chromosome 20q13 [53]. The identification of genes involved in the development of DICAs will continue as more studies are performed. In 2016, Arslan et al. found that MMP-2 might be an etiological factor involved in the development of DICAs [54].

\section{(2) Combination with other congenital diseases}

Fibromuscular dysplasia (FMD) might genetically predispose patients to DICAs. For instance, Paltseva et al. (2015) found that ICA walls 
with pathological tortuosity are observed in FMD patients and present with impaired vascular elastic properties due to the destruction of elastic fibers and a decreased abundance of smooth muscle cells, which result in the enhancement of MMP-9 activity and the induction of tissue matrix degradation [55]. This study demonstrated that the pathological changes associated with FMD could result in DICAs. Ballotta et al. (2005) analyzed 78 elongated carotid arteries with coiling or kinking and found atypical and typical patterns of FMD; the authors concluded that FMD might play an important role in the development of DICAs [56]. In addition, Sethi et al. (2014) confirmed a significantly higher prevalence of " $\mathrm{S}$ "-curve DICAs in FMD patients [57].

In addition to FMD, strong associations between DICAs and abdominal aortic aneurysms have been reported. For instance, a study conducted in 1999 found that degenerative dysplastic changes could be observed in the tunica media in all DICA specimens from patients with aortic aneurysms. These results suggest that a primary arterial disorder of the tunica media could serve as the basis for both conditions [4]. Other rare abnormalities could also be present; for instance, bilateral eagle syndrome with associated ICA kinking and significant stenosis can occur [58]. In addition, arterial tortuosity and ICA aneurysms can occur in the case of Loeys-Dietz syndrome type IB with mutation p.R537P in the TGFBR2 gene [59]. These observations support a congenital origin of at least some DICAs.

\section{Clinical manifestation}

\subsection{General characteristics}

In DICAs, kinking is more common than tortuosity and coiling. Females are predominantly affected by kinking and coiling, whereas the two sexes are equally affected by tortuosity. The incidence rate of DICAs increases with increasing age, and the incidence of ICA tortuosity is high in the elderly, particularly in patients older than 70 years $[3,36]$. DICAs can occur as bilateral and unilateral lesions, but unilateral lesions are more common and are most frequently located in the lower half of the ICA. Approximately $75 \%$ of morphological abnormalities are localized 2-4 $\mathrm{cm}$ proximal to the carotid bifurcation $[39,60]$.

\subsection{Symptoms resulting from an insufficient blood supply}

DICAs can result in symptoms of the brain and eyes due to an insufficient blood supply, but not all DICAs can produce these clinical symptoms because DICAs account for $4 \%-20 \%$ of cases with an insufficient blood supply [17, 19, 61]. Of the DICA types, the coiling type is not considered a risk factor for ischemic events due to its weak association with symptoms. The kinking type, even if not associated with atherosclerotic plaques of the carotid bifurcation, might be associated with symptoms [30], which most commonly appear due to transitory hypotension during sleep or sudden and extreme movement of the head and neck [20, 23].

\section{(1) Cerebrovascular insufficiency and ischemia}

DICAs can cause cerebrovascular insufficiency that produces dyscirculatory encephalopathy, vertigo, diplopia, transitory ischemic attacks or infarction [28, 62, 63]. The III-IV grades of cerebrovascular insufficiency tend to produce symptoms [17]. Hemispheric symptoms might be caused by DICAs through thromboembolic or hemodynamic mechanisms, particularly when kinking is combined with carotid stenosis [64]. In rare conditions, kinking can also cause carotid occlusion. For instance, Brachlow et al. (1992) reported that in a 30-year-old man with carotid kinking who underwent a craniotomy for glioblastoma, head rotation associated with the operation resulted in carotid occlusion and cerebral ischemia, which culminated in brain death during the postoperative period [65]. In addition, among children, coiling is often the reason for reduced cognitive capacity, slow neuropsychological development and focal or grand mal convulsions [66]. However, rotation of the head and neck has no significant influence on the intracranial blood flow in a tortuous ICA [67].

\section{(2) Ocular vascular insufficiency}

The ophthalmic artery is the first branch of the intracranial ICA and plays an important role in the ocular blood supply. DICAs can result in ocular vascular insufficiency, resulting in visual impairments. The onset patterns of these symptoms can be divided into transient, acute and chronic patterns, which include amaurosis fugax, uveitis, retinal and ocular neuropathy. [68, 69]. Of these symptoms, amaurosis fugax and macular dystrophy show the highest frequency [69].

\subsection{Symptoms resulting from the mass effect}

DICAs can be present with a pulsatile cervical mass [70, 71]. For instance, Zheng et al. (2007) reported an asymptomatic submandibular mass, and computed tomography angiography showed a kinked ICA with a "U" shape [42]. Extremely tortuous DICAs can divert their route into the pharyngeal wall and narrow pyriform sinus, which results in the DICAs presenting with a pharyngeal bulge and pulsation [9, 72]. Therefore, awareness of DICAs is very important 
during pharyngeal surgical procedures because inadvertent injury or ligation of a tortuous cervical ICA during procedures for the treatment of peritonsillar abscesses, adenoid surgery or tonsillectomy can result in serious complications, including massive hemorrhage [6, 73-75]. In addition to pharyngeal bulge and pulsation, DICAs can co-occur with pharyngeal foreign body sensation and odynophagia [76]. Persistent obstructive sensation in the throat and dyspnea might occur, and these symptoms are caused by a narrow pharyngeal space resulting from ICA tortuosity [77]. In addition, bilateral tortuosity of the ICA can affect the pharyngeal wall and could be a cause of snoring [78].

\subsection{Other symptoms}

\section{(1) Pulsatile tinnitus}

According to the vessel of origin, pulsatile tinnitus can be classified as arterial or venous [79]. Occasionally, DICAs can present with arterial pulsatile tinnitus when these abnormalities occur close to the cranium base. For instance, Sismanis et al. (2008) described three patients with head bruit or objective tinnitus. All of these patients were found to have tortuosities of the ICA below the cranium base, and one of the patients also had a coiling ICA [80].

\section{(2) Hemilingual spasm}

ICA tortuosity could stretch the hypoglossal nerve and produce clinical symptoms. For instance, Heckmann et al. (2005) described a 59-year-old woman who presented with paroxysmal spasms of the left side of her tongue and concluded that the symptoms were due to compression resulting from ICA tortuosity [81]. These symptoms are similar to intracranial trigeminal neuralgia, glossopharyngeal neuralgia and hemifacial spasm, and ICA compression induced focal demyelination with consequent ectopic excitation and hyperactivity of the hypoglossal nerve [82].

\section{Image examination}

At present, several imaging techniques, including Doppler ultrasonography, computed tomography angiography (CTA), magnetic resonance angiography (MRA) and digital subtraction angiography (DSA), can be used as diagnostic tools for the assessment of DICAs.

\subsection{Doppler ultrasonography}

Doppler ultrasonography is a non-invasive, easily repeatable and rapid diagnostic imaging technique that can provide useful data for the morphological evaluation of DICAs. For instance, Pellegrino et al. performed an epidemiological study of 1220 DICAs imaged by color Doppler ultrasonography, and the authors showed the validity of this method [3]. Because coiling and kinking of the ICA can produce luminal narrowing, which could lead to turbulent blood flow, Doppler scanning can be performed to judge the rectilinearity of the ICA after surgery and easily observe the blood flow turbulence [83]. Therefore, Doppler ultrasonography is useful for obtaining hemodynamic information and for performing DICA functional studies.

\subsection{CTA and MRA}

CTA is used to detect the morphology of the cervical segment of ICAs and can even be used to diagnose some microaneurysms [84]. Moreover, 3D image reconstruction of CTAs is a more effective means of classifying morphological variations of the ICA and for detecting ICA abnormalities; therefore, this method can be used to reduce the risk of serious complications during neck surgery [85, 86]. In addition to CTA, MRA is another useful non-invasive method for diagnosing DICAs [87]. For instance, Tomiya et al. (1995) performed MRA in 13 patients with DICAs and obtained very clear images of ICA tortuosity. Contrast MRA was often more effective for the diagnosis of DICAs [77]. Therefore, MRA is considered a good choice for the diagnosis of DICAs [88-90].

\subsection{DSA}

DSA remains the gold standard for the diagnosis of cervical and intracranial vessel diseases [91]. For DICAs, DSA can provide hemodynamic data and can show the morphology of DICAs in detail. The 3D reconstruction obtained through DSA can provide additional information about DICAs [92]. However, DSA cannot show the pathological changes of the arterial wall of DICAs, which requires CTA or MRA imaging.

\subsection{Examination of cerebral perfusion}

DICAs, particularly the kinking type, can result in decreased cerebral perfusion, and this effect has been confirmed by nuclear medicine examinations. For instance, Trackler et al. (1974) administered 99mTc-pertechnetate in an intravenous bolus to a patient with recurrent hemiparesis associated with kinking of the ICA and found diminished cerebral perfusion [93]. Thus, the perfusion of blood flow examinations is significant, and these results suggest that CT perfusion, MR perfusion and SPECT analyses are useful and convenient methods.

\section{Therapeutic methods}

Some DICAs, particularly symptomatic kinking 
DICAs, should be treated surgically [94, 95]. Some patients can die from a major stroke due to occlusions resulting from DICAs that are not surgically corrected [4]. In addition, the management of some asymptomatic DICAs with pathological kinking can prevent ischemic stroke [96]. Gavrilenko et al. (2012) performed a comparison of surgical and conservative treatments for the pathological kinking of ICA and found that surgical management of the pathological kinking of the ICA is an effective method for preventing progression of cerebrovascular insufficiency [97]. In addition, the reconstructive operations are more effective when pathological tortuosity of the ICA is combined with atherosclerotic stenosis $[94,98]$.

\subsection{Therapeutic indications}

The indications for DICA surgical intervention are determined based on the degree of insufficient blood supply, the hemodynamic significance of pathological tortuosity and the presence of intimal proliferation in the zone of maximal bending $[99,100]$. Gavrilenko et al. (2014) proposed therapeutic indications for DICAs in detail: (i) ICA stenosis $\geq 60 \%$ with atherosclerotic plaques and any degree of cerebrovascular insufficiency; (ii) ICA stenosis < $60 \%$ with atherosclerotic plaques, a moderate to severe degree of cerebrovascular insufficiency in combination with either "S"- or "C"-shaped DICAs, a linear blood flow rate $\geq 110 \mathrm{~cm} / \mathrm{s}$ and a turbulent blood flow [98].

In addition, the fact that the ICA/common carotid artery velocity ratio is greater than 2 is significant [101, 102]. Moreover, reports have suggested that absolute indications for operative intervention in patients with ICAs with pathological tortuosity comprise coiling and kinking with a linear blood velocity higher than $180 \mathrm{~cm} / \mathrm{s}$ [86]. However, surgical indications for DICAs remain controversial. For instance, some studies concluded that there is no evidence to support extension of this surgical indication to asymptomatic patients with carotid kinking [101].

\subsection{Surgical treatment}

There are several methods for the treatment of DICAs, and most of these correct the bending and shortening of the ICA. ICA shortening can restore normal brain blood flow to prevent cerebrovascular insufficiency, and these procedures include end-to-end anastomosis with resection of the excessive ICA, carotid endarterectomy (CEA) with or without resection of the excessive ICA, in situ reimplantation of the ICA by grafting, shortening of the ICA by suturing and ICA dilatation by patch-grafting [103-105].

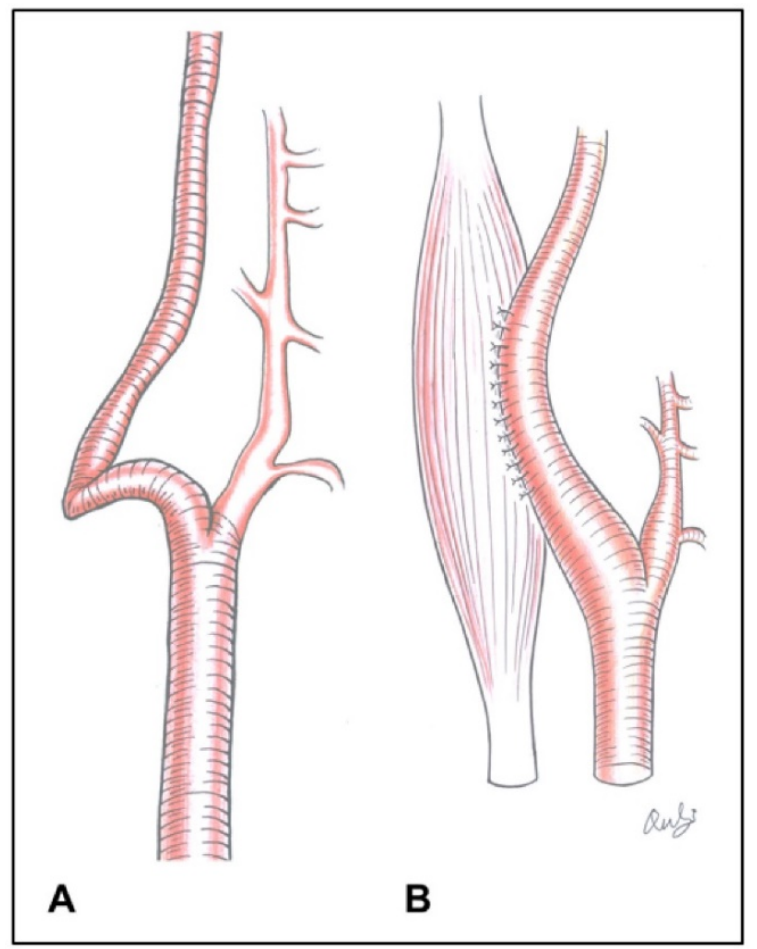

Figure 3. Surgical correction of the bending of DICAs. A: Preoperation, B: Postoperation.

\section{(1) Changing the bending of DICAs}

If the curve of DICAs can be corrected, the blood flow from the ICA to the brain and eyes might increase. In these instances, arteriotomy might not be needed. Several methods have been described to address this issue. Székely et al. (2001) described a method for treating kinking. First, the carotid bifurcation and the anterior portion of the digastric muscle are exposed, and the ICA is then mobilized, which might result in disappearance of the ventral and lateral bends. Finally, the tendon of the digastric muscle is sectioned next to the hyoid bone. The ICA is positioned lateral to the muscle, and the digastric muscle is then repaired with sutures behind the vessel [106]. In another technique reported in 1951, Riser et al. used a piece of the sheath of the sternocleidomastoid muscle to correct the vessel, which proved effective and resulted in improvement of the patient's clinical symptoms [107]. This technique is shown in Figure 3.

\section{(2) End-to-end anastomosis}

End-to-end reconstruction is a good choice for some DICAs, but treatment grouping is necessary. In 2012, Dadashov et al. divided the treatment of ICA kinking into two groups: type I-pathological kinking 
without intimal proliferation and type II-pathological kinking with intimal proliferation. The operation for type I involves resection of the ICA with reimplantation into the native vascular bed, whereas the operation for type II patients involves resection of the kinking area of the ICA with end-to-end anastomosis to remove the septal portion [99]. In type II kinking, the ICA is often transected at the origin and shortened by reimplantation on the bulb [101]. In addition, in cases in which significant ICA stenosis and kinking coexist, resection of the involved segment with end-to-end anastomosis of the posterior wall combined with patch angioplasty using the resected autogenous arterial segment constitutes a convenient and satisfactory reconstruction method [108]. In some cases, repairing the patch is necessary. This technique is illustrated in Figure 4.

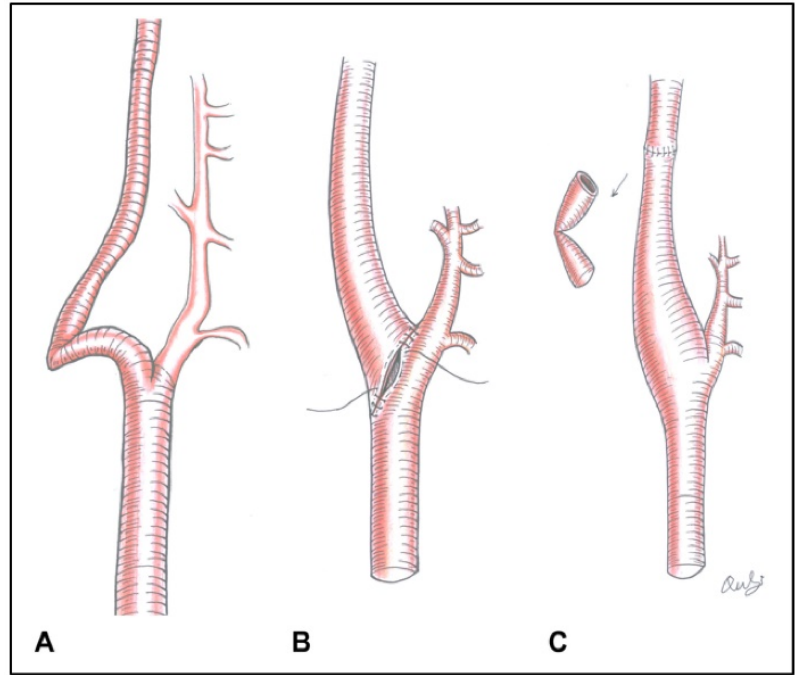

Figure 4. End-to-end anastomosis of DICAs. A: Preoperation, B: ICA-to-bulb anastomosis to shorten the ICA, C: End-to-end anastomosis to shorten the ICA.

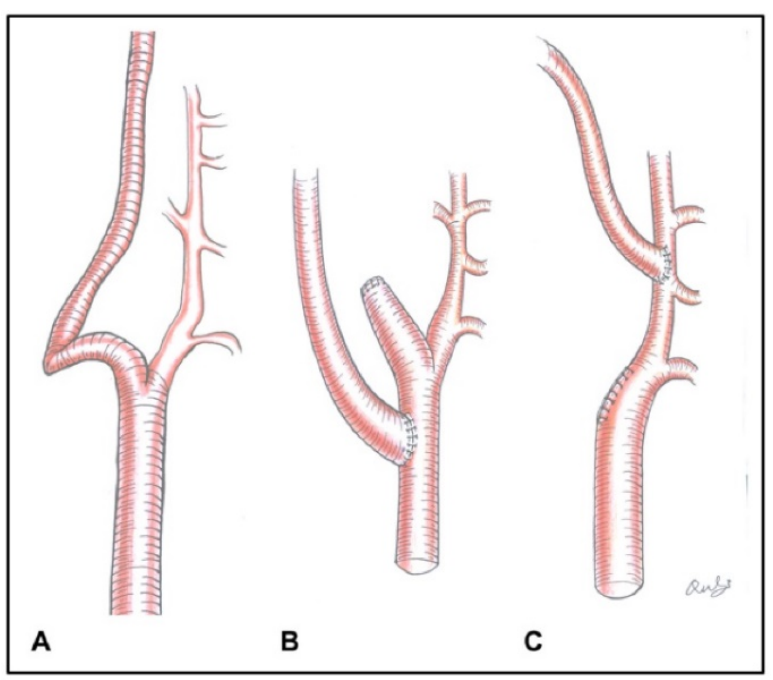

Figure 5. End-to-side reimplantation. A: Preoperation, B: End-to-side CCA, C: End-to-side ECA.

\section{(3) End-to-side reimplantation}

Caudal end-to-side reimplantation of the ICA to the common carotid artery or the external carotid artery is an ideal operation for DICAs. Ballotta et al. (2005) described this procedure. First, the ICA is first transected at the bulb with an incision almost longitudinal to the common carotid artery. Subsequently, after straightening and dilating the ICA, a large, matching elliptic longitudinal window is cut in the lateral wall of the common carotid artery at the level of the reimplantation site, and the ICA is then reimplanted in the common carotid artery caudal end-to-side [56]. In some cases, the external artery is a good choice, particularly when kinking covers a substantial segment of the ICA. The diseased arterial segment is resected, and the distal ICA is reconstructed by transposition with side-to-end anastomosis onto the external carotid artery [101]. This technique is shown in Figure 5.

\section{(4) CEA with a patch}

CEA can correct ICA kinking in symptomatic cases and prevent ischemic stroke [1]. Poorthuis et al. (2014) described this technique and referred to it as "posterior transverse plication". After performing CEA, sutures are placed in the longitudinal direction at the edges of the arteriotomy to create a posterior pouch, which is closed by continuous sutures that are tied outside of the ICA. The lateral remainders are then closed, and the arteriotomy is closed with a patch, which straightens the ICA [109]. This technique, which was described as the "common carotid artery imbrication" technique by Falkensammer et al. in 2007, is similar to the "posterior transverse plication" technique. The difference between these two techniques is that the posterior wall of the common carotid artery is also subjected to imbrication [110]. This technique is shown in Figure 6.

\section{(5) Eversion CEA with resection of excess ICA}

For pathological tortuosity of the ICA combined with atherosclerotic stenosis, eversion CEA with resection of the excess ICA is a good choice. For this technique, the ICA is reimplanted into the ostium [98]. Microaneurysms present in the ICA wall can be managed by resection of the arterial portion with patch repair or by transposing the artery into the previous ostium [83]. For cases of ICA kinking combined with stenosis, eversion CEA with resection of the ICA is optimal [111]. If closing the carotid artery proves difficult, patch angioplasty could be necessary [112]. This technique is shown in Figure 7. 


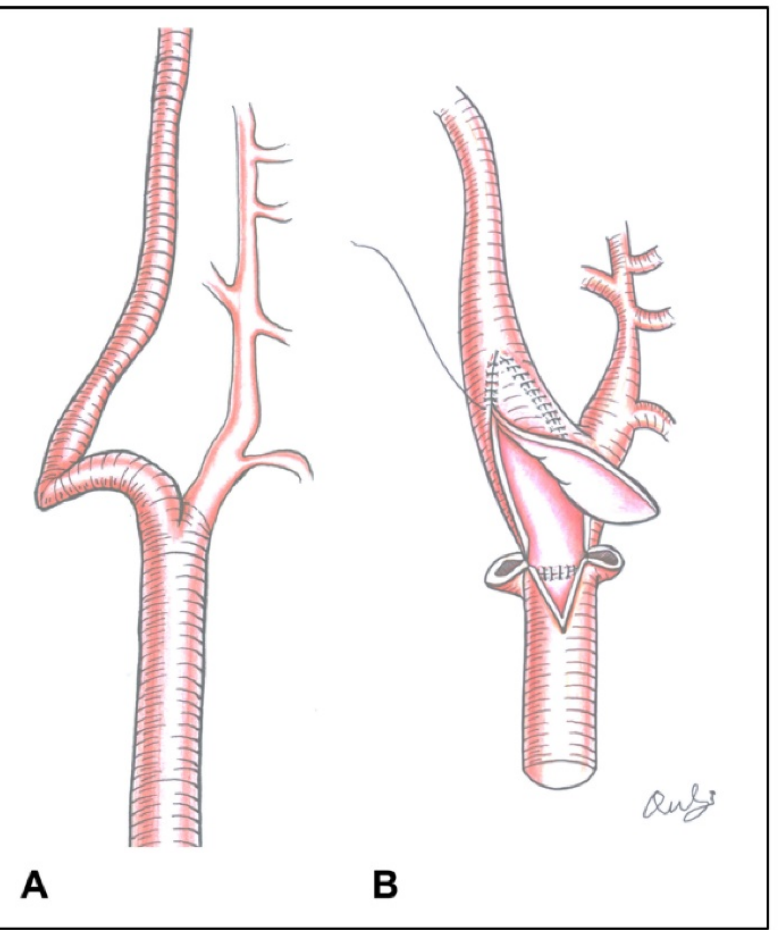

Figure 6. Carotid endarterectomy with a patch. A: Preoperation, B: "Common carotid artery imbrication" technique.

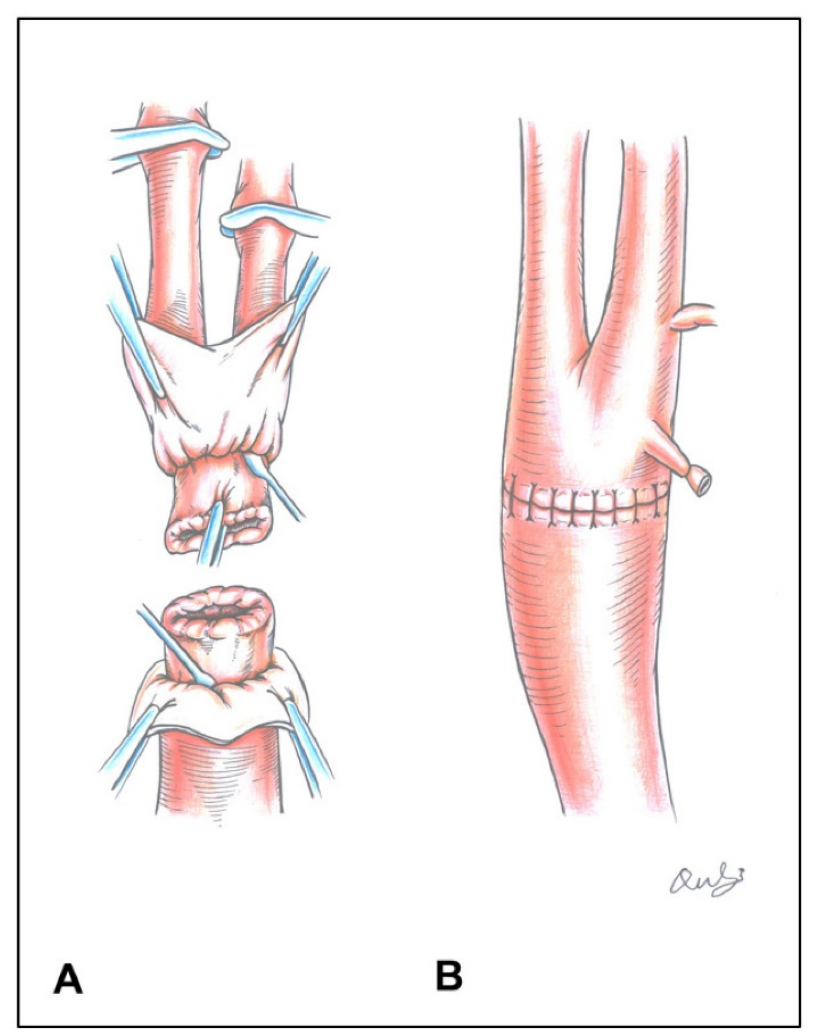

Figure 7. Eversion CEA with resection of the excess ICA. A: Intraoperation, B: Postoperation.

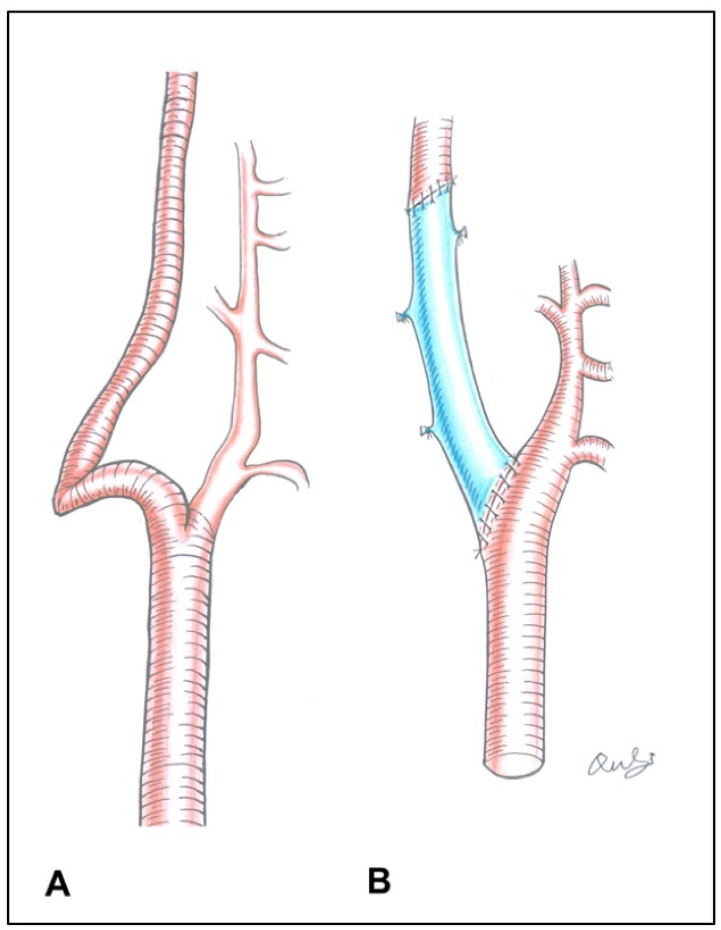

Figure 8. Bypass grafting. A: Preoperation, B: Postoperation.

\section{(6) Bypass grafting}

If transposition is not feasible, bypass grafting is the last resort and can be performed using the autogenous greater saphenous vein as the bypass conduit. During this procedure, the kinked ICA is resected, and a common-to-internal carotid saphenous graft is inserted. An artificial blood vessel can be considered an alternative conduit if the saphenous vein is unavailable [101]. This technique is shown in Figure 8.

\subsection{Carotid angioplasty and stenting}

Carotid artery stenting (CAS) has become a major therapeutic option for symptomatic carotid stenosis, and the role of CAS in the management of severe vessel elongation and kinking is unclear, although it might be feasible in select cases [113-115]. For instance, Wang et al. (2011) treated 12 patients with symptomatic CAS and kinking, and the placement of 14 self-expandable stents reduced the mean degree of stenosis from $85.6 \%$ before CAS to $11.2 \%$ after CAS. The angle of kinking was improved from less than $90^{\circ}$ to more than $120^{\circ}$, and no incidents of perioperative procedure-related stroke or transient ischemic attack occurred [64]. In addition, for dissection of the cervical ICA associated with tortuous tonsillar loop anatomy, the ICA can be safely and effectively recanalized using CAS, with a high long-term patency rate and low rate of procedural risks [116]. 
Table 1. Outline and key points of DICAs

\begin{tabular}{|c|c|c|}
\hline Outline & Key points & $\begin{array}{l}\text { Recommended } \\
\text { documents }\end{array}$ \\
\hline Introduction & $\begin{array}{l}\text { DICAs occur in } 10-25 \% \text { of the population. In a large study of } 1220 \text { Italian subjects examined by Pellegrino et al. in } 1998,316 \\
\text { presented with DICA, corresponding to an incidence rate of } 25.9 \% \text {. }\end{array}$ & {$[1-3]$} \\
\hline Definition & $\begin{array}{l}\text { Metz et al. (1961) and Weibel et al. (1965) classified DICAs into three types, namely tortuous, coiling and kinking. Furthermore, } \\
\text { according to Metz et al., kinking can be divided into three grades, Grade I-III. }\end{array}$ & {$[11-16]$} \\
\hline Hemodynamics & $\begin{array}{l}\text { The cerebral hemodynamic changes are mainly associated with the degree of the bending of DICAs, and cerebral hemodynamic } \\
\text { reduction mainly depends on the value of the angle of a smooth turn. }\end{array}$ & {$[21,22]$} \\
\hline Pathogenesis & $\begin{array}{l}\text { DICAs are not associated with atherosclerotic risk factors, including hypertension, hypercholesterolemia, diabetes mellitus and } \\
\text { cigarette smoking. Many factors, including embryological maldevelopment and age-related loss of elasticity in the vessel wall, are } \\
\text { involved in DICAs. }\end{array}$ & {$[28,29,36-38]$} \\
\hline Clinical manifestation & $\begin{array}{l}\text { DICAs can result in symptoms of the brain and eyes due to insufficient blood supply, but not all DICAs can produce these clinical } \\
\text { symptoms because DICAs account for } 4 \%-20 \% \text { of cases of insufficient blood supply. DICAs can present with a pulsatile cervical } \\
\text { mass, a pharyngeal bulge and pulsation. Occasionally, DICAs can present with arterial pulsatile tinnitus hemilingual spasms. }\end{array}$ & {$[9,17,19,61,72]$} \\
\hline Image examination & $\begin{array}{l}\text { Doppler ultrasonography, CTA, MRA and DSA can be used as diagnostic tools for the assessment of DICAs. Doppler } \\
\text { ultrasonography is a non-invasive, easily repeatable and rapid diagnostic imaging technique that can provide useful data for the } \\
\text { morphological evaluation of DICAs. CTA and MRA are very competent for detecting the morphology of the cervical segment of } \\
\text { the ICA. DSA remains the gold standard for the diagnosis of cervical and intracranial vessel diseases. However, DSA cannot show } \\
\text { the pathological changes of the arterial wall of DICAs. Sometimes, the examination of cerebral perfusion is useful. }\end{array}$ & {$[3,77,84,92]$} \\
\hline Therapeutic indications & $\begin{array}{l}\text { Gavrilenko et al. (2014) proposed therapeutic indications for DICAs in detail: (i) ICA stenosis } \geq 60 \% \text { with atherosclerotic plaques } \\
\text { and with any degree of cerebrovascular insufficiency; (ii) ICA stenosis }<60 \% \text { with atherosclerotic plaques, a moderate to severe } \\
\text { degree of cerebrovascular insufficiency in combination with either "S"- or "C"-shaped DICAs, a linear blood flow rate } \geq 110 \mathrm{~cm} / \mathrm{s} \\
\text { and a turbulent blood flow. In addition, the finding that the ICA/common carotid artery velocity ratio is greater than } 2 \text { is } \\
\text { significant. }\end{array}$ & {$[98,101,102]$. } \\
\hline Therapeutic methods & $\begin{array}{l}\text { Several methods have been developed for the treatment of DICAs, and these include changing the bending of DICAs, end-to-end } \\
\text { anastomosis, end-to-side reimplantation, CEA with a patch, eversion CEA with resection of the excess ICA, bypass grafting and } \\
\text { carotid angioplasty and stenting. According to the type of DICAs, different surgical methods can be selected. }\end{array}$ & $\begin{array}{l}{[98,101,106,} \\
108,116]\end{array}$ \\
\hline $\begin{array}{l}\text { Prognosis and } \\
\text { complications }\end{array}$ & $\begin{array}{l}\text { Anatomical reconstruction together with correction and elimination of the affected segments of the ICA might prevent progressive } \\
\text { cerebrovascular symptoms and is associated with low morbidity and mortality rates. The appropriate treatment of DICAs can } \\
\text { effectively prevent ischemic stroke. Moreover, many complications can accompany the treatment of DICAs. }\end{array}$ & {$[83,117,121]$} \\
\hline
\end{tabular}

\section{Prognosis and complications}

\subsection{Prognosis}

The appropriate treatments for DICAs can result in good outcomes. Anatomical reconstruction together with correction and elimination of the affected segments of the ICA might prevent progressive cerebrovascular symptoms and is associated with low morbidity and mortality rates [117]. For instance, Dadashov et al. (2012) treated a total of 105 patients with pathological kinking of the ICA through a total of 117 reconstructive operations and obtained good outcomes [99], and better results were observed in patients subjected to eversion CEA with resection of the excess ICA [98]. The end-to-side reimplantation of symptomatic isolated carotid elongations with coiling or kinking is effective for stroke prevention [56]. Other surgical procedures consisting of shortening of and reimplantation in the common carotid artery, bypass grafting and transposition into the external carotid artery are also associated with good outcomes [118].

The appropriate treatment for DICAs can effectively prevent ischemic stroke [83]. For instance, Wiechowski et al. (1988) performed surgery on 10 kinking and nine loop DICAs that coincided with transient ischemic attacks, reversible stroke and completed stroke and reported no postoperative neurological complications. Follow-up studies during a period of 1 to 6 years revealed no recurrence of cerebral ischemia [119]. In addition, reconstructive operations of DICAs can increase cerebral blood flow and improve cognitive functions [86]. Similar to cerebrovascular insufficiency, ocular ischemia can be resolved by surgical intervention $[69,120]$.

\subsection{Complications}

Arteriotomies for the treatment of DICAs have numerous risks and complications, including narrowing of the lumen, impatency of the suture and postoperative occlusion caused by mural thrombosis because the endarterectomized section of the ICA is thrombogenic, and shortening of the desobstructed part of the ICA might reduce the risk of thrombosis [121]. For instance, Gavrilenko et al. (2014) reported one patient who developed thrombosis of the reconstruction zone with development of ischemic-type acute cerebral circulation impairment [98]. In addition, postoperative restenosis can occur. For instance, in a study conducted by Illuminati et al. in 2008, six patients developed restenosis of the ICA after bypass grafting, shortening angioplasty and transposition of the ICA onto the ECA [101].

In addition to ischemic complications, rare late infections can occur following the arteriotomy of DICAs. For instance, Petar et al. (2010) described a patient who experienced bilateral ICA reconstruction to resolve ICA kinking, and after five years, the patient became partially symptomatic, showing signs of dizziness, vertigo and visible bilateral neck pulsatile masses. In this case, the final treatment was 
surgery and aneurysmal sac resection followed by end-to-end arterial reconstruction. Staphylococcus aureus from a right-sided wound was cultured, antibiotics were administered, and a good outcome was obtained [122]. In summary, many complications can accompany the treatment of DICAs.

\section{Summary}

DICAs are not uncommon ICA diseases and can be classified by their tortuosity, coiling and kinking. Due to blood flow reduction, DICAs can result in symptoms of the brain and eyes due to insufficient blood supply. In addition, DICAs can be present with a pharyngeal bulge and pulsation. The diagnostic tools for DICAs include Doppler ultrasonography, CTA, MRA and DSA. Some DICAs, particularly those with symptomatic kinking, should be treated surgically, and the appropriate treatments for DICAs have their own surgical indications. Several methods, including correction of the bending of ICAs and shortening of ICAs, have been developed for the treatment of DICAs. The appropriate treatments for DICAs can result in good outcomes and are associated with low morbidity and mortality rates. However, despite the success of surgical reconstruction, an appropriate therapeutic treatment remains the subject of numerous debates due to the lack of multicentric, randomized and prospective studies. Here, we provide a typical case of DICA in which end-to-end anastomosis to shorten the ICA was performed. This case is shown in Figure 9.
A

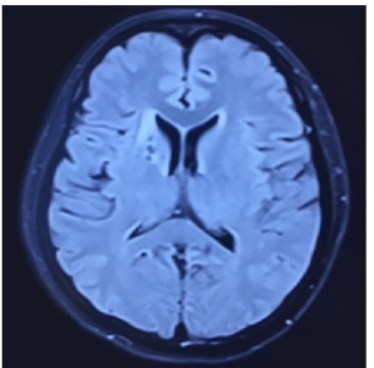

C

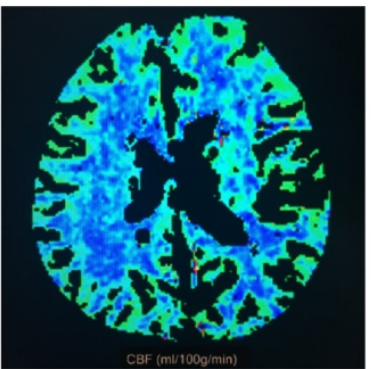

E

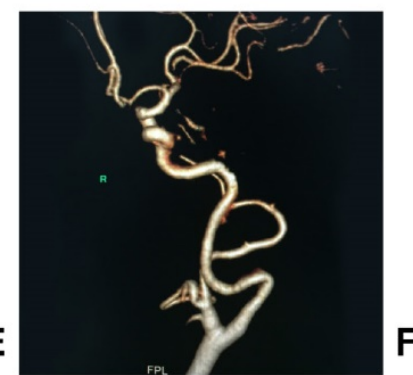

B

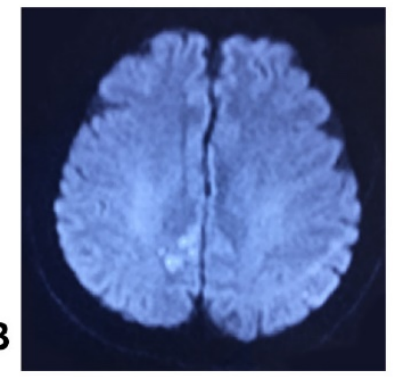

D

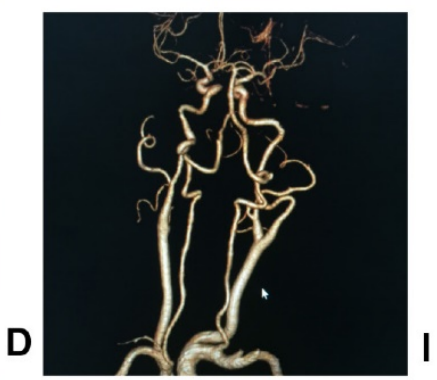

$\mathbf{F}$

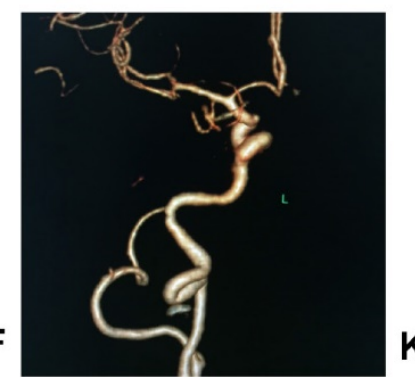

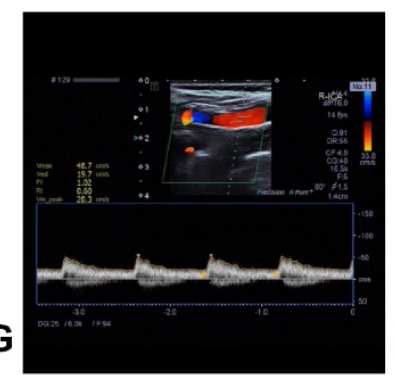
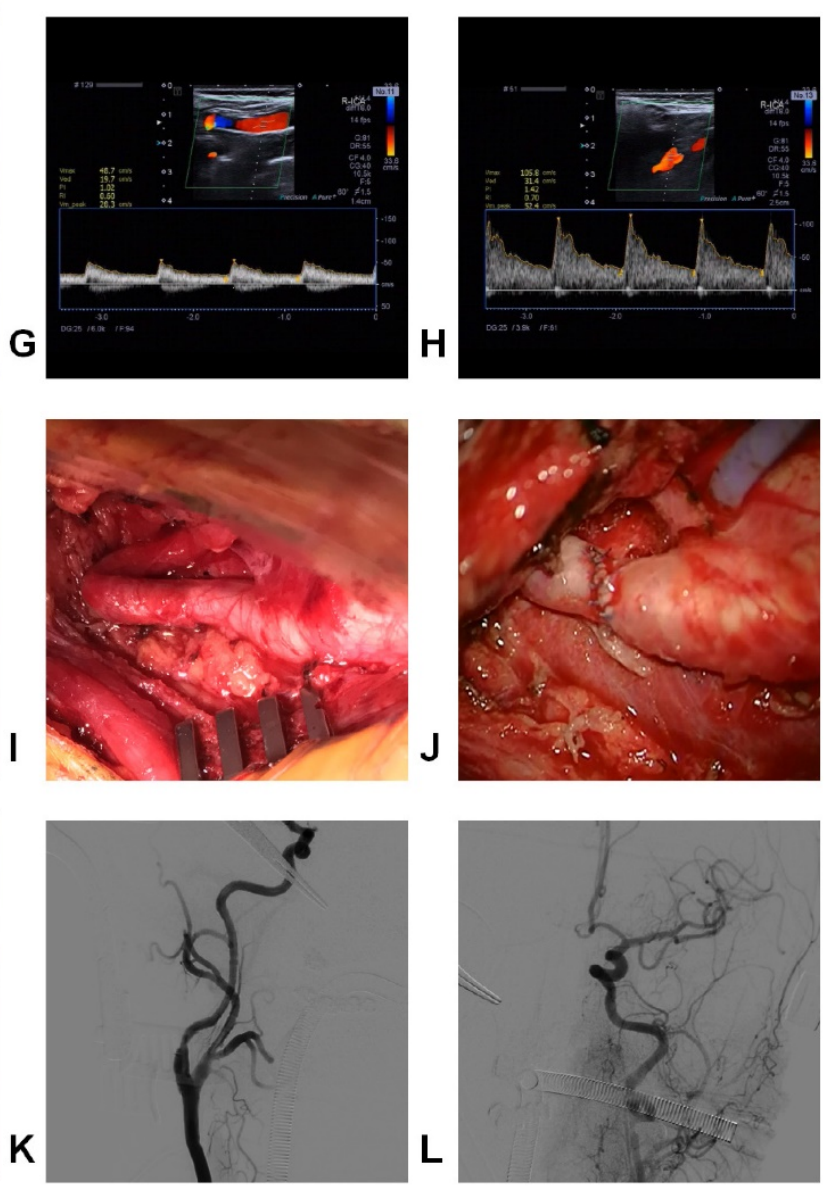

Figure 9. Images of a typical case. A-B: MRI showed infarction of the right hemisphere, C: Perfusion MRI showed a reduction of cerebral blood flow in the right hemisphere, D-F: The CTA showed bilateral kinkings, and the right one was serious. G-H: The Doppler ultrasound showed that the proximal blood flow of the right ICA kinking was $48.7 \mathrm{~cm} / \mathrm{s}$, and the distal blood flow was $105.8 \mathrm{~cm} / \mathrm{s}$, I-J: The operation showed that the kinking was removed, and end-to-end anastomosis was performed to shorten the ICA. K-L: The intraoperative DSA showed that the ICA recovered its normal shape.

\section{Competing Interests}

The authors have declared that no competing interest exists.

\section{References}

1. Cvetko E. Concurrence of bilateral kinking of the extracranial part of the internal carotid artery with coiling and tortuosity of the external carotid artery--a case report. Rom J Morphol Embryol. 2014; 55: 433-5.

2. Schenk $P$, Temmel A, Trattnig S, Kainberger F. [Current aspects in diagnosis and therapy of carotid artery kinking]. HNO. 1996; 44: 178-85. 
3. Pellegrino L, Prencipe G, Vairo F. [Dolicho-arteriopathies (kinking, coiling, tortuoosity) of the carotid arteries: study by color Doppler ultrasonography]. Minerva Cardioangiol. 1998; 46: 69-76.

4. Ballotta E, Da Giau G, Bottio T. Elongation of the internal carotid artery and abdominal aortic aneurysm: is there a relationship? J Cardiovasc Surg (Torino). 1999; 40: 21-6.

5. Perdue GD, Barreca JP, Smith RB, 3rd, King OW. The significance of elongation and angulation of the carotid artery: a negative view. Surgery. 1975; 77: 45-52.

6. Huemer M, Emminger W, Trattnig S, Freilinger M, Wandl-Vergesslich $\mathrm{K}$. Kinking and stenosis of the carotid artery associated with homolateral ischaemic brain infarction in a patient treated with cyclosporin A. Eur J Pediatr. 1998; 157: 599-601.

7. Ballotta E, Abbruzzese E, Thiene G, Bottio T, Dagiau G, Angelini A, et al. The elongation of the internal carotid artery: early and long-term results of patients having surgery compared with unoperated controls. Ann Vasc Surg. 1997; 11: 120-8.

8. Beigelman R, Izaguirre A, Robles M, Grana D, Ambrosio G, Milei J. Kinking of carotid arteries is not a mechanism of cerebral ischemia: a functional evaluation by Doppler echography. Int Angiol. 2011; 30: 342-8.

9. Pfeiffer J, Ridder GJ. A clinical classification system for aberrant internal carotid arteries. Laryngoscope. 2008; 118: 1931-6.

10. Vannix RS, Joergenson EJ, Carter R. Kinking of the internal carotid artery. Clinical significance and surgical management. Am J Surg. 1977; 134: 82-9.

11. Weibel J, Fields WS. Tortuosity, Coiling, and Kinking of the Internal Carotid Artery. Ii. Relationship of Morphological Variation to Cerebrovascular Insufficiency. Neurology. 1965; 15: 462-8.

12. Weibel J, Fields WS. Tortuosity, Coiling, and Kinking of the Internal Carotid Artery. I. Etiology and Radiographic Anatomy. Neurology. 1965; 15: 7-18.

13. Metz H, Murray-Leslie RM, Bannister RG, Bull JW, Marshall J. Kinking of the internal carotid artery. Lancet. 1961; 1: 424-6.

14. Leipzig TJ, Dohrmann GJ. The tortuous or kinked carotid artery: pathogenesis and clinical considerations. A historical review. Surg Neurol. 1986; 25: 478-86.

15. Carcoforo P, Rocca T, Navarra G, Occhionorelli S, Traina L, Mascoli F [Morphologic anomalies of the extracranial internal carotid artery. Our experience]. Minerva Cardioangiol. 1997; 45: 37-41.

16. Mascoli F, Mari C, Liboni A, Virgili T, Marcello D, Mari F, et al. The elongation of the internal carotid artery. Diagnosis and surgical treatment. J Cardiovasc Surg (Torino). 1987; 28: 9-11.

17. Vollmar J, Nadjafi AS, Stalker CG. Surgical treatment of kinked internal carotid arteries. Br J Surg. 1976; 63: 847-50.

18. Wang L, Zhao F, Wang D, Hu S, Liu J, Zhou Z, et al. Pressure Drop in Tortuosity/Kinking of the Internal Carotid Artery: Simulation and Clinical Investigation. Biomed Res Int. 2016; 2016: 2428970.

19. Koskas F, Bahnini A, Walden R, Kieffer E. Stenotic coiling and kinking of the internal carotid artery. Ann Vasc Surg. 1993; 7: 530-40.

20. Stanton PE, Jr., McClusky DA, Jr., Lamis PA. Hemodynamic assessment and surgical correction of kinking of the internal carotid artery. Surgery. 1978; 84: 793-802.

21. Derrick JR, Estess M, Williams D. Circulatory Dynamics in Kinking of the Carotid Artery. Surgery. 1965; 58: 381-3.

22. Kaplan ML, Bontsevich DN. [Effect of the form of pathological tortuosity of the internal carotid artery on cerebral haemodynamics]. Angiol Sosud Khir. 2013; 19: 102-6.

23. Fields WS. Selection of patients with ischemic cerebrovascular disease for arterial surgery. World J Surg. 1979; 3: 147-54.

24. Benedetto F, Massara M, Lentini S, Spinelli F. A case of aneurysm and kinking of the extracranial internal carotid artery. Asian Cardiovasc Thorac Ann. 2012; 20: 705-7.

25. Noad RL, O'Donnell ME, McCavert M, Gardner R, Lee B, Lau LL. A carotid artery aneurysm with a twist: case report and review. Ir J Med Sci. 2012; 181: $321-4$.

26. Nenezic D, Tanaskovic S, Radak D, Babic S, Gajin P. Primary repair of internal carotid artery aneurysm secondary to kinking and cystic medial degeneration. Vasc Endovascular Surg. 2013; 47: 304-9.

27. La Barbera G, La Marca G, Martino A, Lo Verde R, Valentino F, Lipari D, et al. Kinking, coiling, and tortuosity of extracranial internal carotid artery: is it the effect of a metaplasia? Surg Radiol Anat. 2006; 28: 573-80.

28. Quattlebaum JK, Jr., Wade JS, Whiddon CM. Stroke associated with elongation and kinking of the carotid artery: long-term follow-up. Ann Surg. 1973; 177: $572-9$.

29. Sho E, Nanjo H, Sho M, Kobayashi M, Komatsu M, Kawamura K, et al. Arterial enlargement, tortuosity, and intimal thickening in response to sequential exposure to high and low wall shear stress. J Vasc Surg. 2004; 39: 601-12.

30. Saba L, Mallarini G. Correlation between kinking and coiling of the carotid arteries as assessed using MDCTA with symptoms and degree of stenosis. Clin Radiol. 2010; 65: 729-34.

31. Onakpoya I, O'Sullivan J, Heneghan C, Thompson M. The effect of grapefruits (Citrus paradisi) on body weight and cardiovascular risk factors: A systematic review and meta-analysis of randomized clinical trials. Crit Rev Food Sci Nutr. 2017; 57: 602-12.

32. Ghilardi G, Longhi F, De Monti M, Bortolani E. [Carotid kinking and arterial hypertension. Preliminary results of the OPI program]. Minerva Cardioangiol. 1993; 41: 287-91.
33. Del Corso L, Moruzzo D, Conte B, Agelli M, Romanelli AM, Pastine F, et al. Tortuosity, kinking, and coiling of the carotid artery: expression of atherosclerosis or aging? Angiology. 1998; 49: 361-71.

34. Oliviero U, Scherillo G, Casaburi C, Di Martino M, Di Gianni A, Serpico R, et al. Prospective evaluation of hypertensive patients with carotid kinking and coiling: an ultrasonographic 7-year study. Angiology. 2003; 54: 169-75.

35. Pancera P, Ribul M, Presciuttini B, Lechi A. Prevalence of carotid artery kinking in 590 consecutive subjects evaluated by Echocolordoppler. Is there a correlation with arterial hypertension? J Intern Med. 2000; 248: 7-12.

36. Prencipe G, Pellegrino L, Vairo F, Tomaiuolo M, Furio OA. [Dolichoarteriopathy (kinking, coiling,tortuosity,)) of the carotid arteries and cardiovascular risk factors]. Minerva Cardioangiol. 1998; 46: 1-7.

37. Pellegrino L, Prencipe G. [Dolichoarteriopathies (kinking, coiling, tortuosity) of carotid arteries and atherosclerotic disease: an ultrasonographic study]. Cardiologia. 1998; 43: 959-66.

38. Yu K, Zhong T, Li L, Wang J, Chen Y, Zhou H. Significant Association between Carotid Artery Kinking and Leukoaraiosis in Middle-Aged and Elderly Chinese Patients. J Stroke Cerebrovasc Dis. 2015; 24: 1025-31.

39. Pellegrino L, Prencipe G, Ferrara V, Correra M, Pellegrino PL. [Bilateral and monolateral dolichoarteriopathies (Kinking, Coiling, Tortuosity) of the carotid arteries and atherosclerotic disease. An ultrasonographic study]. Minerva Cardioangiol. 2002; 50: 15-20.

40. Choudhry FA, Grantham JT, Rai AT, Hogg JP. Vascular geometry of the extracranial carotid arteries: an analysis of length, diameter, and tortuosity. J Neurointerv Surg. 2016; 8: 536-40.

41. Kamenskiy AV, Pipinos II, Carson JS, MacTaggart JN, Baxter BT. Age and disease-related geometric and structural remodeling of the carotid artery. J Vasc Surg. 2015; 62: 1521-8.

42. Zheng JW, Zhang WL, Fan XD, Zhang ZY. Elongation and tortuosity of the bilateral internal carotid artery presenting as a pulsatile cervical mass: report of a case. J Oral Maxillofac Surg. 2007; 65: 1370-2.

43. Kozakova M, Palombo C, Morizzo C, Hojlund K, Hatunic M, Balkau B, et al. Obesity and carotid artery remodeling. Nutr Diabetes. 2015; 5: e177.

44. Derubertis BG, Hynecek RL, Kent KC, Faries PL. Carotid tortuosity in patients with prior cervical radiation: increased technical challenge during carotid stenting. Vasc Endovascular Surg. 2011; 45: 619-26.

45. Barbour PJ, Castaldo JE, Rae-Grant AD, Gee W, Reed JF, 3rd, Jenny D, et al. Internal carotid artery redundancy is significantly associated with dissection. Stroke. 1994; 25: 1201-6.

46. Meghani M, Siddique MN, Bhat T, Samarneh M, Elsayegh S. Internal carotid artery redundancy and dissection in a young cocaine abuser. Vascular. 2013; 21: 243-5.

47. Baracchini C, Farina F, Tonello S, Citton V, Meneghetti G, Ballotta E, et al. Endothelial dysfunction in carotid elongation. J Neuroimaging. 2013; 23: 18-20.

48. Saba L, Argiolas GM, Sumer S, Siotto P, Raz E, Sanfilippo R, et al. Association between internal carotid artery dissection and arterial tortuosity. Neuroradiology. 2015; 57: 149-53.

49. Hamada J, Kai Y, Morioka M, Kaku T, Korematsu K, Ushio Y. Tortuosity of the Cervical Segment of the Internal Carotid Artery in AVM Patients. Interv Neuroradiol. 1997; 3 Suppl 2: 133-6.

50. Beigelman R, Izaguirre AM, Robles M, Grana DR, Ambrosio G, Milei J. Are kinking and coiling of carotid artery congenital or acquired? Angiology. 2010; 61: 107-12.

51. Yildiz S, Cece H, Karayol S, Ziylan Z. Concurrence of the tortuosity of bilateral common and left internal carotid arteries in a case with common origin of the innominate trunk and left common carotid artery. Surg Radiol Anat. 2010; 32: 797-9.

52. Voevoda MI, Kulikov IV, Maksimov VN, Smirnova Iu V. [Association of Sp4 gene polymorphism with pathological tortuosity of internal carotid arteries]. Kardiologiia. 2009; 49: 46-9.

53. Zaidi SH, Peltekova V, Meyer S, Lindinger A, Paterson AD, Tsui LC, et al. A family exhibiting arterial tortuosity syndrome displays homozygosity for markers in the arterial tortuosity locus at chromosome 20q13. Clin Genet. 2005; 67: 183-8.

54. Arslan Y, Arslan IB, Pekcevik Y, Sener U, Kose S, Zorlu Y. Matrix Metalloproteinase Levels in Cervical and Intracranial Carotid Dolichoarteriopathies. J Stroke Cerebrovasc Dis. 2016; 25: 2153-8.

55. Paltseva EM, Oskolkova SA, Polyakova VO, Krylova YU, Ivanova AG, Abramyan AV, et al. [The structure of the internal carotid artery wall in pathological tortuosity]. Arkh Patol. 2015; 77: 3-8.

56. Ballotta E, Thiene G, Baracchini C, Ermani M, Militello C, Da Giau G, et al. Surgical vs medical treatment for isolated internal carotid artery elongation with coiling or kinking in symptomatic patients: a prospective randomized clinical study. J Vasc Surg. 2005; 42: 838-46; discussion 46.

57. Sethi SS, Lau JF, Godbold J, Gustavson S, Olin JW. The S curve: a novel morphological finding in the internal carotid artery in patients with fibromuscular dysplasia. Vasc Med. 2014; 19: 356-62.

58. Radak D, Tanaskovic S, Kecmanovic V, Babic S, Popov P, Gajin P. Bilateral Eagle Syndrome with Associated Internal Carotid Artery Kinking and Significant Stenosis. Ann Vasc Surg. 2016; 34: 271 e15-8.

59. Kilic E, Alanay Y, Utine E, Ozgen-Mocan B, Robinson PN, Boduroglu K. Arterial tortuosity and aneurysm in a case of Loeys-Dietz syndrome type IB with a mutation p.R537P in the TGFBR2 gene. Turk J Pediatr. 2012; 54: 198-202.

60. Mukherjee D, Inahara T. Management of the tortuous internal carotid artery. Am J Surg. 1985; 149: 651-5. 
61. Ogretmenoglu O. Asymptomatic looping of the internal carotid artery: a case report. Kulak Burun Bogaz Ihtis Derg. 2004; 12: 144-6.

62. Ohata K, Hakuba A, Shirahata N, Nishimura S. [Kinking of cervical internal carotid artery causing acute infantile hemiplegia. Case report]. Neurol Med Chir (Tokyo). 1982; 22: 1029-34.

63. Quattlebaum JK, Jr., Upson ET, Neville RL. Stroke associated with elongation and kinking of the internal carotid artery: report of three cases treated by segmental resection of the carotid artery. Ann Surg. 1959; 150: 824-32.

64. Wang LJ, Wang DM, Liu JC, Lu J, Qi P, Li D, et al. [Endovascular management of symptomatic carotid stenosis combined with kinking]. Zhonghua Wai Ke Za Zhi. 2011; 49: 105-8.

65. Brachlow J, Schafer M, Oliveira H, Jantzen JP. [A fatal intraoperative cerebral ischemia following kinking of the internal carotid artery?]. Anaesthesist. 1992; 41: 361-4.

66. Najafi H, Javid H, Dye WS, Hunter JA, Julian OC. Kinked Internal Carotid Artery. Clinical Evaluation and Surgical Correction. Arch Surg. 1964; 89: 134-43.

67. Malek AK, Hilgertner L, Szostek M. The effect of internal carotid artery elongation on intracranial blood flow. Eur J Vasc Surg. 1994; 8: 677-81.

68. Vlasov SK. [Changes in the organ of vision in pathological tortuosity and atherosclerotic stenosis of the carotid arteries]. Vestn Oftalmol. 2010; 126: $58-62$.

69. Gavrilenko AV, Kuklin AV, Kisileva TN, Abramian AV, Omarzhanova II. [Immediate and remote results of surgical treatment of patients presenting with pathological tortuosity of internal carotid arteries and accompanying ocular ischaemic syndrome]. Angiol Sosud Khir. 2013; 19: 114-9.

70. Johnson RE, Stambaugh KI, Richmond H, Balbuena L. Tortuous internal carotid artery presenting as an oropharyngeal mass. Otolaryngol Head Neck Surg. 1995; 112: 479-82

71. Hosokawa S, Mineta $\mathrm{H}$. Tortuous internal carotid artery presenting as a pharyngeal mass. J Laryngol Otol. 2010; 124: 1033-6.

72. Ozcan KM, Ozcan I, Selcuk A, Pasaoglu L, Hatipoglu HG, Dere H. Tortuous internal carotid artery narrowing pyriform sinus: two cases. Clin Imaging. 2008; $32: 220-2$

73. Kamal Muhammad J, Penrose-Stevens A, Framinan A, Halpin SF, Shone GR. [Tortuosity of the internal carotid artery and its implications for the oropharyngeal and skull base surgery]. Neurocirugia (Astur). 2002; 13: 225-8.

74. Lien $\mathrm{CF}$, Weng $\mathrm{HH}$, Lin BS, Liu CF, Wu TC, Lin YS. Effect of carotid artery aberrancy on the distance between the vessel and nasopharyngeal subsites. J Chin Med Assoc. 2014; 77: 253-7.

75. Paulsen F, Tillmann B, Christofides C, Richter W, Koebke J. Curving and looping of the internal carotid artery in relation to the pharynx: frequency, embryology and clinical implications. J Anat. 2000; 197 (Pt 3): 373-81.

76. Cong TC, Duan X, Gao WH, Zhao EM, Yang XD, Wang H, et al. [Tortuosity and kinking of cervical segment of internal carotid artery: an analysis of 7 cases]. Zhonghua Er Bi Yan Hou Tou Jing Wai Ke Za Zhi. 2012; 47: 913-7.

77. Tomiya Y, Chiba S, Moriyama H, Kikuchi Y, Ohta M. [Eighteen cases of tortuosity of the internal carotid--usefulness of MR-angiography in diagnosis]. Nihon Jibiinkoka Gakkai Kaiho. 1995; 98: 1367-72.

78. Eyibilen A, Baykara M, Ozbay AS. [A possible cause of snoring: bilateral tortuosity of the internal carotid artery]. Kulak Burun Bogaz Ihtis Derg. 2008; 18: $250-2$

79. Corr P, Tsheole-Marishane L. Pulsatile tinnitus. Br J Radiol. 2001; 74: 669-70.

80. Sismanis A, Girevendoulis A. Pulsatile tinnitus associated with internal carotid artery morphologic abnormalities. Otol Neurotol. 2008; 29: 1032-6.

81. De Ridder D, Alessi G, Lemmerling M, Fransen H, De Waele L. Hemilingual spasm: a new neurosurgical entity? Case report. J Neurosurg. 2002; 97: 205-7.

82. Moller AR. Vascular compression of cranial nerves: II: pathophysiology. Neurol Res. 1999; 21: 439-43.

83. Kazakov YI, Pavlov EV, Federyakin DV, Ivanova OV, Vardak A. [Peculiarities of diagnosis and surgical policy in elderly patients with pathological tortuosity of the internal carotid artery]. Angiol Sosud Khir. 2015; 21: 112-7.

84. Mamedov FR, Arutiunov NV, Usachev D, Lukshin VA, Beliaev A, Mel'nikova-Pitskhelauri TV, et al. [Neuroradiological diagnostics of atherosclerotic lesions and kinking of the carotid arteries in determination of indications to surgical treatment]. Zh Vopr Neirokhir Im N N Burdenko. 2011; 75: 3-10; discussion

85. Nagata T, Masumoto K, Hayashi Y, Watanabe Y, Kato Y, Katou F. Three-dimensional computed tomographic analysis of variations of the carotid artery. J Craniomaxillofac Surg. 2016; 44: 734-42.

86. Kazakov Iu I, Ivanova OV, Pospelova AM, Vardak A. [Diagnostic peculiarities, surgical policy, and efficacy of reconstructive operations in pathological tortuosity of internal carotid arteries]. Angiol Sosud Khir. 2015; 21: $153-7$.

87. Kang CK, Park CA, Lee DS, Lee YB, Park CW, Kim YB, et al. Velocity measurement of microvessels using phase-contrast magnetic resonance angiography at 7 Tesla MRI. Magn Reson Med. 2016; 75: 1640-6.

88. Okami K, Onuki J, Ishida K, Kido T, Takahashi M. Tortuosity of the internal carotid artery--report of three cases and MR-angiography imaging. Auris Nasus Larynx. 2001; 28: 373-6.

89. Duncan IC, Sher BJ, Pencharz M. Kinking of bilateral internal carotid arteries that mimics posttraumatic radiographic prevertebral soft-tissue widening. AJR Am J Roentgenol. 2002; 179: 1352.
90. Pelaez JM, Levine RL, Hafeez F, Dulli DA. Tortuosity of carotid and vertebral arteries: a magnetic resonance angiographic study. J Neuroimaging. 1998; 8: 235-9.

91. Jadhav AP, Jovin TG. Vascular imaging of the head and neck. Semin Neurol. 2012; 32: 401-10.

92. Jalali A, Srinivasan VM, Chinnadurai P, Kan P, Arthur A, Duckworth EA. Two-color 3D-3D fusion of selective rotational cerebral angiograms: a novel approach to imaging in cerebrovascular neurosurgery. J Neurointerv Surg. 2016; 8: 1056-60.

93. Trackler RT, Mikulicich AG. Diminished cerebral perfusion resulting from kinking of the internal carotid artery. J Nucl Med. 1974; 15: 634-5.

94. Ilic M, Tanaskovic S, Ilijevski N, Radak D. [Acute reversible ischaemic neurological deficit induced by internal carotid artery kinking--case report]. Srp Arh Celok Lek. 2011; 139: 92-4.

95. Grego F, Lepidi S, Cognolato D, Frigatti P, Morelli I, Deriu GP. Rationale of the surgical treatment of carotid kinking. J Cardiovasc Surg (Torino). 2003; 44: 79-85.

96. Gavrilenko AV, Guzenko AS, Kuklin AV, Kochetkov VA. [Prevention of ischemic stroke in patients with asymptomatic lesions of carotid arteries]. Angiol Sosud Khir. 2012; 18: 35-9.

97. Gavrilenko AV, Abramian AV, Kuklin AV. [Comparative analysis of the outcomes of surgical and conservative treatment of patients with pathological kinking of carotid arteries]. Angiol Sosud Khir. 2012; 18: 93-9.

98. Gavrilenko AV, Kuklin AV, Khripkov AS, Abramian AV. [Assessment of efficacy of reconstructive operations on carotid arteries in combination of stenosis and pathological tortuosity]. Angiol Sosud Khir. 2014; 20: 116-22.

99. Dadashov SA, Lavrent'ev AV, Frolov KB, Vinogradov OA, Dziundzia AN, Ul'ianov ND. [Surgical treatment of pathological kinking of the internal carotid artery]. Angiol Sosud Khir. 2012; 18: 116-21.

100. van Alphen HA. Kinking of the carotid artery: indications for surgery and surgical procedure. Clin Neurol Neurosurg. 1977; 80: 92-9.

101. Illuminati G, Ricco JB, Calio FG, D'Urso A, Ceccanei G, Vietri F. The results in a consecutive series of 83 surgical corrections of symptomatic stenotic kinking of the internal carotid artery. Surgery. 2008; 143: 134-9.

102. Macchi C, Gulisano M, Giannelli F, Catini C, Pratesi C, Pacini P. Kinking of the human internal carotid artery: a statistical study in 100 healthy subjects by echocolor Doppler. J Cardiovasc Surg (Torino). 1997; 38: 629-37.

103. Henly WS, Cooley DA, Gordon WB, Jr, Debakey ME. Tortuosity of the internal carotid artery. Report of seven cases treated surgically. Postgrad Med. 1962; 31: 133-44.

104. Tetik O, Yurekli I, Yilik L, Akhan G, Gurbuz A. Surgical treatment of symptomatic coiling or kinking internal carotid artery. Vascular. 2010; 18: 294-6.

105. Gyurko G, Revesz J. New surgical procedures for the management of carotid kinking. Acta Chir Hung. 1990; 31: 325-31.

106. Szekely G, Csecsei GI. Anteposition of the internal carotid artery for surgical treatment of kinking. Surg Neurol. 2001; 56: 124-6.

107. Riser M, Gerard J, Ribaut L. Dolichocarotide interne avec syndrome vertigineux. Rev Neurol 1951;85:145e51.

108. Gugulakis AG, Matsagas MI, Vasdekis SN, Giannakakis SG, Lazaris AM, Sechas MN. Evolving techniques in the treatment of carotid artery kinking: the use of resected redundant arterial segment. Am Surg. 2001; 67: 67-70.

109. Poorthuis MH, Brand EC, Toorop RJ, Moll FL, de Borst GJ. Posterior transverse plication of the internal carotid artery to correct for kinking. J Vasc Surg. 2014; 59: 968-77.

110. Falkensammer J, Hakaim AG, Oldenburg WA, Berland TB. Common carotid artery imbrication as an adjunct to carotid endarterectomy to prevent postoperative carotid kinking. Am Surg. 2007; 73: 276-8.

111. Gavrilenko AV, Abramian AV, Kuklin AV, Kochetkov VA. [Results of surgical treatment of patients with internal carotid artery kinking depending on methods of its reconstruction]. Khirurgiia (Mosk). 2014: 4-9.

112. Collins PS, Orecchia P, Gomez E. A technique for correction of carotid kinks and coils following endarterectomy. Ann Vasc Surg. 1991; 5: 116-20.

113. Ahmadi RA, Schillinger M, Haumer M, Willfort A, Minar E. Carotid stenting in a case of combined kinking and stenosis. Cardiovasc Intervent Radiol. 2001; 24: 197-9.

114. Faggioli G, Ferri M, Gargiulo M, Freyrie A, Fratesi F, Manzoli L, et al. Measurement and impact of proximal and distal tortuosity in carotid stenting procedures. J Vasc Surg. 2007; 46: 1119-24.

115. Bates MC, Kyer PD, Kavasmaneck C, AbuRahma A, Crotty B. Stent-supported angioplasty correction of symptomatic critical carotid angulation. W V Med J. 2003; 99: 22-4.

116. Rahal JP, Gao B, Safain MG, Malek AM. Stent recanalization of carotid tonsillar loop dissection using the Enterprise vascular reconstruction device. J Clin Neurosci. 2014; 21: 1141-7.

117. Radonic V, Baric D, Giunio L, Buca A, Sapunar D, Marovic A. Surgical treatment of kinked internal carotid artery. J Cardiovasc Surg (Torino). 1998; 39: 557-63.

118. Illuminati G, Calio FG, Papaspyropoulos V, Montesano G, D'Urso A Revascularization of the internal carotid artery for isolated, stenotic, and symptomatic kinking. Arch Surg. 2003; 138: 192-7.

119. Wiechowski SW, Mierzecki AM. Surgical treatment of cerebrovascular insufficiency in patients with pathological elongation of the internal carotid artery. Eur J Vasc Surg. 1988; 2: 105-10. 
120. Smirnova Iu V. On the advisability of surgical treatment of children with kinking of the internal carotid artery. Angiol Sosud Khir. 2007; 13: 101-7.

121. Dirrenberger RA, Sundt TM, Jr. Carotid endarterectomy. Temporal profile of the healing process and effects of anticoagulation therapy. J Neurosurg. 1978; 48: 201-19.

122. Petar P, Slobodan T, Srdjan B, Dragoslav N, Djordje R. Extracranial internal carotid artery pseudoaneurysms after kinking reconstruction. Vascular. 2010; 18: 356-62. 